\title{
Body Weight Reduction Improves Both Reflux Symptoms and Esophageal Physiologic Examination
}

\author{
Shou-Wu Lee ${ }^{\mathrm{a}, \mathrm{b}, \mathrm{d}}$, Han-Chung Lien ${ }^{\mathrm{a}, \mathrm{c}}$, Chi-Sen Chang ${ }^{\mathrm{a}, \mathrm{b}}$, Hong-Zen Yeh ${ }^{\mathrm{a}, \mathrm{c}}$
}

\begin{abstract}
A 51-year-old woman with gastroesophageal reflux disease (GERD) had high body weight and body mass index (BMI) initially, and proton-pump inhibitor (PPI) was needed for symptom relief. Three years later, her body weight and BMI were reduced. Improvement of GERD questionnaire scores and 24-hour esophageal $\mathrm{pH}$-metry data were disclosed. No additional PPIs were needed.
\end{abstract}

Keywords: Body weight reduction; Gastroesophageal reflux disease; Obesity

\section{Introduction}

Gastroesophageal reflux disease (GERD) is a chronic disease that has an impact on the everyday lives of affected individuals. The risk factors in patients with GERD are multiple, including age, gender, hiatal hernia, unfavorable lifestyles and so on [1]. Obesity, defined by a body mass index (BMI) over $30 \mathrm{~kg} / \mathrm{m}^{2}$, constitutes a major factor in the etiology of GERD, and a number of studies have reported on the association between reflux symptoms and obesity [2-4]. Wight loss is recommended for GERD patients who are obese or have had recent weight gain [1]. We reported an overweight female who had marked improvements of both GERD symptoms and esophageal physiologic examination results after body weight reduction.

\footnotetext{
Manuscript accepted for publication October 06, 2015

aDivision of Gastroenterology, Department of Internal Medicine, Taichung Veterans General Hospital, Taichung, Taiwan

${ }^{b}$ Department of Internal Medicine, Chung Shan Medical University, Taichung, Taiwan

'Department of Internal Medicine, National Yang-Ming University School of Medicine, Taipei, Taiwan

${ }^{\mathrm{d} C}$ Corresponding Author: Shou-Wu Lee, Division of Gastroenterology, Department of Internal Medicine, Taichung Veterans General Hospital, Taichung, 1650 Taiwan Boulevard, Sec. 4, Taichung 40705, Taiwan.

Email: ericest@vghtc.gov.tw
}

doi: http://dx.doi.org/10.14740/jmc2331w

\section{Case Report}

A 51-year-old woman visited our hospital initially because of persist heartburn sensation and acid regurgitation. She denied of an unfavorable lifestyle such as alcohol drinking and cigarette smoking. Her body weight was $56 \mathrm{~kg}$, height was 149 $\mathrm{cm}$, and BMI was $25.22 \mathrm{~kg} / \mathrm{m}^{2}$. She had completed the GERD questionnaire, including with the severity of symptoms graded on a 3-point Likert scale. Mild, moderate and advanced severity were defined, respectively, as symptoms that can easily be ignored, symptoms that can be easily tolerated and symptoms sufficient to cause interference with normal activities. Her scores of GERD questionnaire were high, and the results were shown in Figure 1.

She underwent an open-access transoral upper gastrointestinal endoscopy, and no obvious esophagogastric erosion was noted. She was further evaluated with the $24 \mathrm{~h}$ esophageal pH-metry (Sleuth; Sandhill Scientific, Inc., Highlands Ranch, CO, USA), and data were analyzed manually using dedicated software (Bioview Analysis; Sandhill Scientific Inc.). The daily acid reflux episodes were 140 times, and the Demeester score was as high as 34.3 (a Demeester score $>14.72$ indicates GERD). The detailed results were displayed in Figure 2. Pro-

\section{GERD questionnaire symptoms severity}

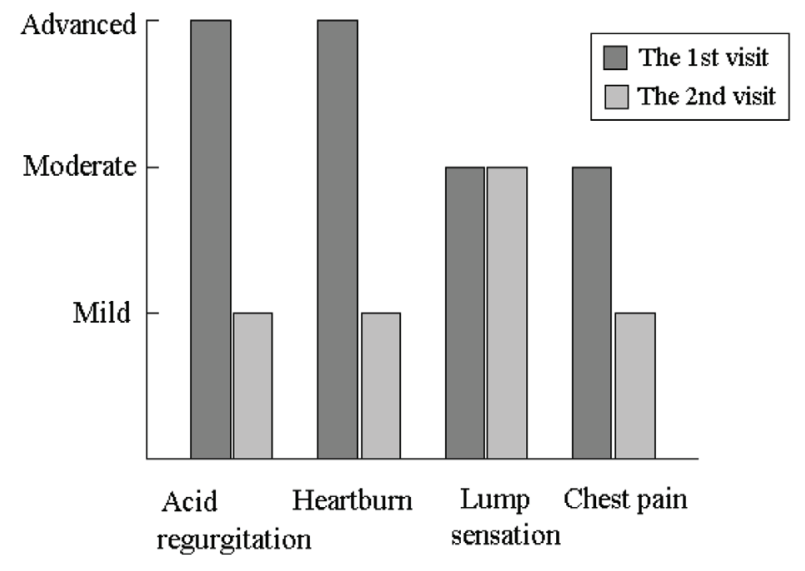

Figure 1. The GERD questionnaire scores of this patient before and after body weight reduction. 
(A) 1st 24-h esophageal pH-metry

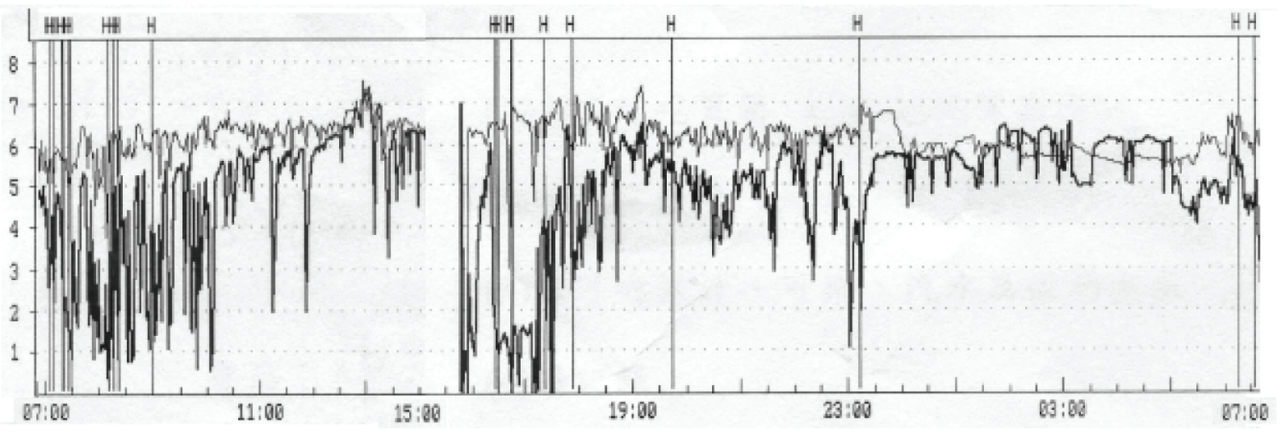

(B) 2nd 24-h esophageal pH-metry

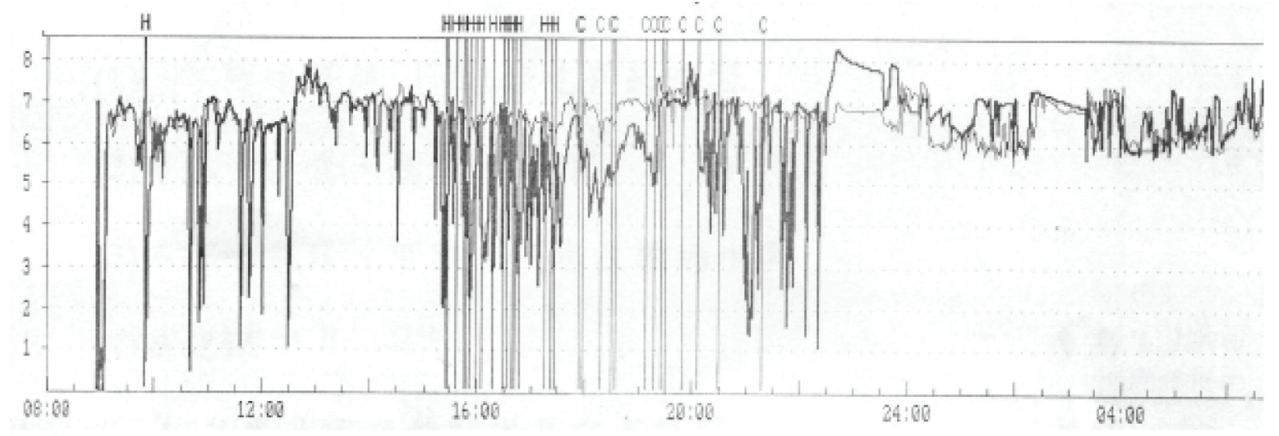

\begin{tabular}{|c|c|c|c|c|}
\hline & $\begin{array}{l}\text { Total reflux } \\
\text { episodes }\end{array}$ & $\begin{array}{l}\text { Longest reflux } \\
\text { episode (min) }\end{array}$ & $\begin{array}{l}\text { Longer than 5 } \\
\text { min episodes }\end{array}$ & $\begin{array}{l}\text { Demeester } \\
\text { scores }\end{array}$ \\
\hline 1st & 140 & 48 & 2 & 34.3 \\
\hline 2nd & 58 & 2 & 0 & 7.5 \\
\hline
\end{tabular}

Figure 2. The $24 \mathrm{~h}$ esophageal $\mathrm{pH}$-metry results of this patient before and after body weight reduction

ton-pump inhibitor (PPI) was prescribed for GERD symptoms, but she lost follow-up then.

Three years later, she came back to our hospital again. Her body weight and BMI were reduced to $44 \mathrm{~kg}$ and $19.81 \mathrm{~kg} / \mathrm{m}^{2}$, respectively. The severity of her reflux symptoms was improved, and the GERD questionnaire results were shown in Figure 1. She received the $24 \mathrm{~h}$ esophageal $\mathrm{pH}$-metry again. The daily acid reflux episodes were 58 times, and the Demeester score was 7.5. The complete results were shown in Figure 2, too. No additional PPIs were needed based on the minimal reflux symptoms.

\section{Discussion}

GERD is one of many diseases clearly linked to obesity. The strong positive association between obesity and GERD symptoms has been convincingly demonstrated in several population-based studies [2-4]. One previous report found obese participants were 2.5 times as likely as those with normal BMI to have reflux symptoms or esophageal erosions [2]. In a recent meta-analysis, a significant association between gastroesophageal reflux (odds ratio, 1.89; 95\% confidence interval, 1.70 2.09) and increasing BMI was found [5]. Furthermore, obese patients with GERD tend to own a poor healthy quality of life than others [6].

One retrospective study, using esophageal $24 \mathrm{~h} \mathrm{pH}$ monitoring to evaluate the patients with GERD symptoms, found that $13 \%$ of the variation of esophageal acid exposure was due to BMI [7]. Another study performed with wireless capsule $\mathrm{pH}$ monitoring during $48 \mathrm{~h}$ disclosed that an increased esophageal acid exposure was five times higher in obese patients with GERD symptoms than in normal weight patients with GERD symptoms [8]. The pathogenesis of obesity in GERD might be associated with increased intra-abdominal pressure, impaired gastric emptying, decreased lower esophageal sphincter pressure and increased frequency of transient sphincter relaxation [6].

Weight gain aggregates the reflux symptoms, and weight 
loss is beneficial for GERD symptoms. A past populationbased study showed that an increase in BMI of more than 3.5 $\mathrm{kg} / \mathrm{m}^{2}$ in women with normal BMI at baseline increased the risk of GERD symptoms (odds ratio, 2.8; 95\% confidence interval, 1.63 - 4.82) as compared to women without weight change. On the contrary, a weight loss amounting to a decrease of BMI of $3.5 \mathrm{~kg} / \mathrm{m}^{2}$ over a period of 14 years decreased the risk of frequent GERD symptoms by nearly $40 \%$ (odds ratio, $0.64 ; 95 \%$ confidence interval, 0.42 - 0.97) as compared to women without weight loss [4]. In another population-based study in Spain, the subjects with a weight gain over $5 \mathrm{~kg}$ coexists with an increased new GERD symptoms (odds ratio, 3.0; 95\% confidence interval, 1.6 - 6.0) [9]. A hospital-based study found a weight loss of $5-10 \%$ in women and $>10 \%$ in men, led to a significant reduction in overall GERD symptoms scores [10]. However, until now, there was no report discussing the differences of esophageal physiologic examination after body weight loss in the individuals with GERD.

To our patient, the BMI was reduced from 25.5 to 19.81 $\mathrm{kg} / \mathrm{m}^{2}$ in a 3 -year period. Not only reflux symptoms, but also esophageal physiologic acidic reflux numbers, got a marked improvement, and PPIs could be discontinued. Our result provides a firm evidence of the beneficial effect of body weight reduction to obesity patients with GERD, and the optimal is to treat the obesity first, as weight loss improves quality of life, and also decreases all the comorbidities associated with obesity such as cardiovascular diseases, diabetes, etc.

\section{Conclusion}

Body weight loss leads to reduction of both reflux symptoms severity and esophageal physiologic acid reflux in the obese patients with GERD.

\section{References}

1. Katz PO, Gerson LB, Vela MF. Guidelines for the diagno- sis and management of gastroesophageal reflux disease. Am J Gastroenterol. 2013;108(3):308-328; quiz 329.

2. El-Serag HB, Graham DY, Satia JA, Rabeneck L. Obesity is an independent risk factor for GERD symptoms and erosive esophagitis. Am J Gastroenterol. 2005;100(6):12431250 .

3. El-Serag H. The association between obesity and GERD: a review of the epidemiological evidence. Dig Dis Sci. 2008;53(9):2307-2312.

4. Jacobson BC, Somers SC, Fuchs CS, Kelly CP, Camargo $\mathrm{CA}$, Jr. Body-mass index and symptoms of gastroesophageal reflux in women. N Engl J Med. 2006;354(22):23402348.

5. Eslick GD. Gastrointestinal symptoms and obesity: a meta-analysis. Obes Rev. 2012;13(5):469-479.

6. Lee SW, Lien HC, Chang CS, Peng YC, Ko CW, Chou MC. Impact of body mass index and gender on quality of life in patients with gastroesophageal reflux disease. World J Gastroenterol. 2012;18(36):5090-5095.

7. Ayazi S, Hagen JA, Chan LS, DeMeester SR, Lin MW, Ayazi A, Leers JM, et al. Obesity and gastroesophageal reflux: quantifying the association between body mass index, esophageal acid exposure, and lower esophageal sphincter status in a large series of patients with reflux symptoms. J Gastrointest Surg. 2009;13(8):1440-1447.

8. Crowell MD, Bradley A, Hansel S, Dionisio P, Kim HJ, Decker GA, DiBaise JK, et al. Obesity is associated with increased 48-h esophageal acid exposure in patients with symptomatic gastroesophageal reflux. Am J Gastroenterol. 2009; 104(3):553-559.

9. Rey E, Moreno-Elola-Olaso C, Artalejo FR, Locke GR, 3rd, Diaz-Rubio M. Association between weight gain and symptoms of gastroesophageal reflux in the general population. Am J Gastroenterol. 2006;101(2):229-233.

10. Singh M, Lee J, Gupta N, Gaddam S, Smith BK, Wani $\mathrm{SB}$, Sullivan DK, et al. Weight loss can lead to resolution of gastroesophageal reflux disease symptoms: a prospective intervention trial. Obesity (Silver Spring). 2013;21(2):284-290. 